\title{
On associations between computers and restaurants: Rapid learning of new associations on a conceptual implicit memory test
}

\author{
KAVITHA SRINIVAS \\ Boston College, Boston, Massachusetts \\ and \\ DANIELLE CULP and SUPARNA RAJARAM \\ State University of New York, Stony Brook, New York
}

\begin{abstract}
A novel event-based conceptual implicit memory test was designed to tap the development of new associations between objects and ad hoc categories. At study, participants were presented with a plausible story that linked an incongruous object (computer) with an ad hoc category (restaurant). At test, participants judged whether a given object was typically found in a restaurant. In Experiment 1, judgment time was significantly slower for the incongruous object (computer) when the story had previously linked the computer to the restaurant, relative to when it had not. Experiment 2 replicated this effect and ruled out the alternative interpretation that this interference effect was attributable to a general slowing of responses to all studied items. Unlike in prior studies, this demonstration of associative priming cannot be attributed to perceptual priming or to test awareness in memory-intact participants. The paradigm therefore offers a unique opportunity to study single-trial conceptual learning in memory-intact and memory-impaired populations.
\end{abstract}

Conceptual measures of implicit memory refer to tests that assess indirect retrieval of prior studied information from associative cues. For instance, participants may be asked to generate exemplars to the category name animal after study of the low-frequency exemplar donkey in a prior experimental session. Prior study tends to enhance the retrieval of low-frequency exemplars on such a category association task, even when participants are unaware that the association task is a memory test (e.g., Carlesimo, 1994; Graf, Shimamura, \& Squire, 1985).

In this article, we focus on the issue of whether indirect retrieval on a conceptual test can allow access to newly formed associations between unrelated concepts (such as restaurants and computers). In other words, can new associations between unrelated concepts be established within a single trial, and if they are, can one gain indirect access to this associative information? This question is theoretically important because it sets the boundary conditions for the types of information that can be accessed through implicit memory. For instance, some have argued that while implicit memory can be used to retrieve preexisting semantic associations (such as animal-donkey) or perceptual representations (facilitated perception of the

\footnotetext{
Experiment 1 of this article constituted D.C.'s undergraduate honors thesis, conducted under the guidance of K.S. Research reported in this article was supported in part by NIH Grant R29MH57345-01. Correspondence should be addressed to K. Srinivas, Department of Psychology, Boston College, Chestnut Hill, MA 02167-3807 (e-mail: srinivas@) bc.edu).
}

word donkey), it cannot be used to retrieve novel contextual associations (e.g., Bower, 1996). Within this framework, new associations between unrelated concepts can be retrieved only through episodic tasks.

Thus far, the evidence that speaks to this issue is not conclusive. This is due in part to the properties of the implicit tests used to access new associations. Specifically, existing implicit tests of new association have usually involved the presentation of unrelated word pairs at study (e.g., kindly-stick and window-reason). The development of new conceptual associations between these unrelated words is assessed by tests of implicit memory under conditions when the study context is recapitulated at test (kindly-stick) relative to when it is not (window-stick). The tests include word stem completion of one member of the pair (e.g., kindly-sti_, Graf \& Schacter, 1985, 1987, 1989; Schacter \& Graf, 1986), perceptual identification of the pair (Paller \& Mayes, 1994), lexical decisions to the pair (Goshen-Gottstein \& Moscovitch, 1995a, 1995b), relatedness judgments of the pair (GoshenGottstein \& Moscovitch, 1995a), and speeded naming of the pair (Moscovitch, Winocur, \& McLachlan, 1986; Musen $\&$ Squire, 1993). Note that in all instances, the critical cuetarget pair is presented in the exact same way at study and at test. This is certainly not the case in conceptual implicit tests of preexisting relations, where the cue bears no perceptual resemblance to the studied item; it is related at a conceptual level (e.g., the cue animal is related only conceptually to the studied target donkey). Note also that with the exception of the relatedness judgment task, all other 
tasks are typical measures of perceptual, and not conceptual, implicit memory (Roediger, Weldon, \& Challis, 1989).

These attributes of implicit tests of new association have led to two key problems in the interpretation of existing findings. First, when an advantage is observed for maintaining the cue-target pairing from study (henceforth referred to as association-specific priming), it is unclear whether this priming reflects perceptual access to studied information or conceptual access. Indeed, the existing evidence seems to favor a perceptual interpretation of association-specific priming rather than a conceptual one. For instance, a change in the modality of studied and tested word pairs eliminates association-specific priming, as does a change in the perceptual gestalt of the pairs (e.g., a change from window-reason to reason-window, GoshenGottstein \& Moscovitch, 1995a, 1995b; Poldrack \& Cohen, 1997; Schacter \& Graf, 1989). This perceptual mediation of association-specific priming is perhaps not surprising given the perceptual nature of most of the tests. However, tests that appear to require conceptual processing, such as the relatedness judgment task used by Goshen-Gottstein and Moscovitch (1995a), have also been reported to contain a perceptual component. ${ }^{\prime}$ This may reflect the fact that cue-target pairs on this task were repeated between study and test, thus allowing a benefit in the perceptual analysis of the pair. Thus, from the existing literature, there seems to be little or no evidence for the retrieval of new associations on implicit tests when perceptual mediation is eliminated as a confound.

A second problem in interpreting the present findings is the problem of test awareness in participants, which is aggravated by the fact that cue-target pairs are repeated in exactly the same format between study and test. Test awareness has been formally assessed in studies by asking participants whether they are aware of the relationship between the implicit memory test and the study phase (Bowers \& Schacter, 1990). In such studies, test-unaware participants do not show any evidence of association-specific priming (Bowers \& Schacter, 1990; Reingold \& GoshenGottstein, 1996; but see Howard, Fry, \& Brune, 1991). Furthermore, amnesics, who are typically test unaware, show impaired association-specific priming relative to controls (Graf \& Schacter, 1985, 1987; Hamann \& Squire, 1995; Hayman, MacDonald, \& Tulving, 1992; Mayes \& Gooding, 1989; Rajaram \& Coslett, 2000; Schacter \& Graf, 1986; Shimamura \& Squire, 1989; Tulving, Hayman, \& MacDonald, 1991). These studies, on the face of it, suggest that the retrieval of new conceptual associations is not possible or is not as efficient through implicit memory.

These considerations from prior studies on conceptual implicit memory for new associations motivated the present research. The goal of our study was to examine whether it is possible to obtain conceptual implicit memory for new associations under conditions that promote conceptual rather than perceptual retrieval, and under conditions that minimize test awareness. To this end, we developed a task with the following features: (1) the cue-target pair presented at study was related at a conceptual level to the pair presented at test (i.e., exact repetition of the cue-target format did not occur), (2) a modality change occurred from study to test, (3) test awareness was minimized and formally assessed, and (4) a strong elaborative structure was provided at encoding to establish the association between cue and target. Briefly, in the test we designed, participants first viewed a picture of an incongruous object (e.g., computer) in a scene (e.g., restaurant). Simultaneously, they heard a dialogue that established a plausible reason for the presence of the incongruous object in the scene. In the dialogue, neither the incongruous object nor the scene was explicitly mentioned; the relationship between the two was based strictly on inference. This dialogue provided the structure for the development of a strong conceptual association between the incongruous object and the scene. After participants viewed and heard 13 such stories, they performed a category judgment test. In the category judgment test, participants judged whether each of six objects (e.g., computer, wrench, wind chime, salt shaker, napkin, wineglass) was typically a member of ad hoc categories that corresponded to the studied scenes (things found in a restaurant). Note that the category name used at test was never mentioned in the dialogue at study; it was related only at a conceptual level to the presented scene. Similarly, the incongruous object (computer) was presented in a modality (picture) different from the tested modality (visual words). Thus, the cue-target pair presented at test was related only at a conceptual level to the studied scene/dialogue. The issue of interest was whether participants would be slower to respond that studied incongruous objects (e.g., computer) did not in fact belong to the category (things found in a restaurant) even when this repetition of the cue-target pair was at an abstract conceptual level.

We hypothesized that if participants did indeed show a slower response to studied incongruous objects, it would reflect implicit access to a new conceptual association between the concept of restaurant and that of computer. We assumed that the association was conceptual rather than perceptual, for the reasons described above. In addition, we note that the modality change in our study involved a switch from pictures to visual words, rather than a switch from auditory words to visual words, as in prior studies. We chose this particular manipulation because a change from pictures to words is more effective in eliminating perceptual priming than a change from the auditory to the visual modality (Rajaram \& Roediger, 1993; Srinivas, 1993; Srinivas \& Roediger, 1990; Weldon \& Roediger, 1987).

Furthermore, to minimize test awareness in our participants, we incorporated the following features in the design of the study. First, study status was not predictive of the category-object relationship on any given trial. For each category (restaurant), both a congruous (napkin) and an incongruous (computer) object, henceforth referred to as targets, were presented to participants at study, and both these targets were paired with the category at test. Second, we designed the test so that studied objects con- 
stituted only a small proportion of the total number of trials $(11 \%)$. Third, associative priming for incongruous objects was deliberately assessed through interference rather than facilitation, because interference is less prone to episodic retrieval strategies (Jacoby, Woloshyn, \& Kelley, 1989). In addition, we formally assessed awareness that the category judgment task was an implicit memory test through the use of a questionnaire and eliminated testaware participants from our analyses (Bowers \& Schacter, 1990).

We report two experiments with this implicit category judgment task. In Experiment 1, we contrasted performance on the implicit category judgment task with an explicit recognition task. Specifically, we predicted that we would find slower performance on studied incongruous targets and faster performance on studied congruous target, relative to corresponding nonstudied items on the implicit category judgment task. For incongruous targets, this result would support the development of a new conceptual association, whereas for congruous targets, this result would be expected from the activation of a preexisting conceptual association (Graf \& Mandler, 1984). In the explicit recognition task, we predicted better recognition performance for incongruous targets, because in the background of related information (e.g., a restaurant scene), the incongruous targets (e.g., a computer) are likely to become distinctive (see Schmidt, 1991). We also expected that explicit recognition would be more prone to reconstructive errors than the implicit category judgment task (see, e.g., Parkin, 1983). As a result, we expected that participants would be more likely to falsely recognize congruous distractors (salt shaker, wineglass) after exposure to the restaurant scene at study relative to incongruous distractors (wrench, wind chime), even though that neither type of object had been presented in the scene or dialogue at study. We predicted that this same effect would not be obtained in the implicit category judgment task because specific associations between distractors and the category names were never developed at study.

\section{EXPERIMENT 1}

\section{Method}

Participants. Ninety-three Boston College undergraduates provided informed consent and participated in the experiment in partial fulfillment of a course requirement.

Materials. On the basis of a norming study administered to 20 participants, each of the 26 ad hoc category names (restaurant) was paired with a unique incongruous (computer) and congruous (napkin) target. Selection of the congruous and incongruous targets was based on at least $96 \%$ agreement among the 20 participants. Four other objects per category were assigned as the congruous (salt shaker, wineglass) and incongruous (wrench, wind chime) distractors per category.

The study stimuli consisted of 26 digitized color photographs of familiar situations that corresponded to the ad hoc categories (e.g., a restaurant scene for the category things found in a restaurant). The incongruous and congruous targets (computer and napkin, respectively) were embedded within these scenes. The presentation of the scenes was synchronized with a digitized auditory dialogue that described plausible reasons for the presence of the incongruous target (computer). For example, the following dialogue was presented with the restaurant scene:

Speaker A: Our waitress keeps forgetting to bring us more napkins.

Speaker B: That's alright. While we wait for our dinners, I can work on

my English paper. It's due in class tomorrow morning.

Speaker A: I suppose you are right. I'm glad I already finished mine.

Note that the dialogue explicitly mentioned the presence of the congruous target (e.g., napkin in the restaurant scene) to draw attention to the presence of the object in the scene. This was done because we hypothesized that participants may fail to attend to the congruous target in the scene, given that the incongruous target (computer in the restaurant) was more likely to capture attention. Also note that the congruous distractors (salt shaker, wineglass) and incongruous distractors (wrench, wind chime) were not included in these study scenes and were presented only at test with the category name.

The stimuli for the test phase consisted of 240 category-object pairs (e.g., things found in a restaurant: computer), which were composed of 40 (26 critical, 14 fillers) different category names each paired with six objects (two targets, four distractors). The appearance of these six category-object pairs was randomized through the course of the experiment.

Design. Two blocks of 13 categories were created and used for counterbalancing across studied and nonstudied conditions. We manipulated test type (implicit category judgment task and explicit recognition task) as a separate between-subjects factor. Forty participants took part in the implicit test and 30 in the explicit test.

Procedure. At study, participants viewed the 20 digitized pictures in a randomized order ( 13 target scenes and 7 fillers) on the computer screen and listened via headphones to a short dialogue that described the actions occurring in the scene. They were asked to rate how well they comprehended the events occurring in the scene and dialogue on a 5-point scale.

After the study phase, participants were given a distractor task of completing analogies for $7 \mathrm{~min}$. During the test phase, participants were randomly assigned to the implicit or explicit test conditions. For both tests, the same items were used to test memory. In the implicit test, participants were instructed to decide whether or not an object belonged in the particular ad hoc category with which it was paired by pressing one of two keys. In the explicit test condition, participants were instructed to decide whether a category-object pair represented a pairing from the scene-dialogue stories presented earlier by pressing one of two keys. Latency to make the category decision or the recognition decision was recorded with millisecond precision by a $C$ program.

Participants in the implicit task subsequently completed a survey that contained three open-ended questions designed to elicit any awareness that the category judgment task was in fact related to the dialogue comprehension task. Specifically, participants were asked if they had used any particular strategy in the comprehension of scenes (the study task), in the completion of the analogies (the distractor task), and in the judgment of category-object relationships (the implicit task). Following the three questions, participants were asked if they noticed a relationship between the study task and the test task. In Experiment 1, 3 participants in the implicit condition stated that they noticed a relationship between the study and test tasks. These test-aware participants were replaced.

\section{Results and Discussion}

Data from the implicit memory task (category judgment) and explicit memory task (recognition) were analyzed separately because of procedural and baseline dif- 
ferences between the two types of tests. On both tests, response time and proportion correct constituted the dependent variables, although response time was the primary measure for category judgment because of ceiling effects in accuracy. Similarly, accuracy data was the primary measure for recognition because of the small number of correct responses available for latency analysis. Analyses are therefore reported for these measures. In the experiments reported in this article, we replaced outlier response times for each participant that exceeded the mean by $2 S D$ with a value that was exactly equal to the mean plus $2 S D$.

Category judgment task. Data from 2 participants with unusually long response times (greater than $2 S D$ ) were deleted from analysis without any effect on the counterbalancing.

Table 1 presents the response times and accuracy for studied and nonstudied targets and distractors. Planned comparisons indicated that performance for incongruous targets (computer) was worse when targets were studied than when they were not $[t(37)=2.95, S E=52.39, p<$ .005 in latency, $t(37)=2.37, S E=.01, p<.03$ in accuracy]. This delayed rejection and reduced accuracy on studied incongruous targets is consistent with our prediction and suggests the acquisition of a newly acquired association between the incongruous object and its paired category. For congruous targets (napkin), we did not observe the predicted facilitation effects; the opposite trend in the latency data, however, was not significant $(t<1)$. In accuracy, the trend in the right direction approached significance $[t(37)=1.66, S E=.02, p<.10]$. For distractors (wineglass or wrench), as expected, we observed no differences in response time or accuracy between the conditions when the category was studied relative to when it was nonstudied [ $t \mathrm{~s}<1$ in all conditions, except in accuracy for incongruous distractors, $t(37)=1.31, S E=.01]$.

To summarize the implicit category judgment data, we obtained the predicted pattern for incongruous objects (computer), which suggested the development of a new association between the object and category. Importantly, retrieval of this new association through implicit memory was not mediated by perceptual processing or by test awareness. In contrast to the predicted pattern obtained for incongruous objects, we failed to observe any facilitation for studied congruous objects (napkin). This latter result was surprising given that this pattern has been observed previously in the literature (e.g., Goshen-Gottstein \& Moscovitch, 1995a), albeit with different tasks. One possible explanation might be that in prior studies, participants were exposed to related targets in isolation, rather than in a context that juxtaposed the encoding of related targets with the encoding of more distinct incongruous targets. As a result, congruous targets (napkin) in our paradigm may have received less attention on average than incongruous targets. Because a reduction in attentional resources reduces facilitation on conceptual implicit tasks (Mulligan, 1997; Mulligan \& Hartman, 1996), the lack of facilitation effects in this experiment could have occurred due to diminished attentional resources. We return to this explanation in the section below.

Recognition memory task. Two participants, with error rates beyond $2 S D$ from the mean, were eliminated from the analysis without any effect on the counterbalancing. Table 1 presents the mean proportion of correct responses for studied and nonstudied targets and distractors. This proportion represents hits for studied targets, correct rejections for nonstudied targets, and correct rejections for studied and nonstudied distractors.

First, as we predicted, incongruous targets (computer) were recognized better than congruous (napkin) targets because they were more distinctive and thus likely captured attention [hits - false alarms, $t(27)=4.79, S E=0.04$, $p<.001]$. This advantage for incongruous targets was found in the accuracy data, but it was not statistically significant in the latency data $[t(27)=1.44, S E=115.15, p>$ .10]. Regardless, the accuracy data suggest a substantial advantage in the recognition of incongruous targets. Once again, this advantage, on the face of it, is inconsistent with prior findings that related pairs are better recognized than unrelated pairs (Dosher \& Rosedale, 1991; GoshenGottstein \& Moscovitch, 1995a). However, we note that in these prior studies, related and unrelated pairs were encoded in isolation. In contrast, in our study, congruous targets were encoded within the context of distinctive incongruous targets. In this respect, the encoding of congruous,

Table 1

Mean Response Times (RTs, in Milliseconds) and Accuracy (in Proportions) for Correct Category Judgments on the Implicit Task, and Correct Episodic Judgments (Hits for Studied Targets and Correct Rejections for Studied Distractors and Nonstudied Targets/Distractors) on the Recognition Task in Experiment 1

\begin{tabular}{|c|c|c|c|c|c|c|c|c|}
\hline \multirow[b]{2}{*}{ Task } & \multicolumn{2}{|c|}{$\begin{array}{c}\text { Incongruous Target } \\
\text { (computer) }\end{array}$} & \multicolumn{2}{|c|}{$\begin{array}{c}\text { Congruous Target } \\
\text { (napkin) }\end{array}$} & \multicolumn{2}{|c|}{$\begin{array}{l}\text { Incongruous Distractor } \\
\text { (wrench, wind chime) }\end{array}$} & \multicolumn{2}{|c|}{$\begin{array}{l}\text { Congruous Distractor } \\
\text { (salt shaker, wineglass) }\end{array}$} \\
\hline & RT & Accuracy & RT & Accuracy & RT & Accuracy & $\mathrm{RT}$ & Accuracy \\
\hline \multicolumn{9}{|c|}{ Implicit; Category Judgment } \\
\hline & 1,984 & .94 & 1,699 & .96 & 1,808 & .93 & 1,830 & .91 \\
\hline & 1,829 & .97 & 1,684 & .93 & 1,809 & .94 & 1,808 & .89 \\
\hline \multicolumn{9}{|c|}{ Recognition; Episodic Judgment } \\
\hline & 2,186 & .72 & 2,352 & .71 & 2,128 & .95 & 2,505 & .64 \\
\hline & 2,052 & .98 & 2,078 & .78 & 1,950 & .97 & 2,220 & .81 \\
\hline
\end{tabular}


related objects is akin to the encoding of related words within a von Restorff paradigm, where memory for similar background items is found to be poorer than memory for the single unrelated item. Under such conditions, it is perhaps not surprising that a disproportionate amount of attention was paid to incongruous targets (computer) relative to the congruous targets (napkin). We therefore suggest that differential attention accounts both for the lack of facilitation for congruous targets on the implicit category judgment task and the advantage for incongruous targets on the recognition task.

Second, as predicted, participants produced more false alarms to congruous distractors (wineglass) than to incongruous distractors (wrench), particularly for studied categories. Specifically, in the accuracy data, there was a main effect of congruity $\left[F(1,27)=33.96, M S_{\mathrm{e}}=.05, p<\right.$ $.01]$, a main effect of study $\left[F(1,27)=29.71, M S_{\mathrm{e}}=.01\right.$, $p<.01$, and more importantly, a significant interaction between the two $\left[F(1,27)=33.35, M S_{\mathrm{e}}=.004, p<.01\right]$. This pattern of responses for distractors indicates reconstructive errors in the explicit recognition task, which is consistent with our hypothesis. Note that the latency data suggested that participants were slower to respond to congruous distractors overall, but this effect failed to interact with study status. Thus in latency, there was a main effect of congruity $\left[F(1,27)=18.45, M S_{\mathrm{e}}=170,392, p<.01\right]$ and a main effect of study $\left[F(1,27)=11.29, M S_{\mathrm{e}}=141,613\right.$, $p<.01]$, but the interaction between the two failed to reach significance $(F<1)$.

Interestingly, we observed no such evidence for reconstructive errors in the implicit category judgment task (i.e., facilitation for congruous distractors such as wineglass or salt shaker) when the objects were never actually presented. The presence of reconstructive errors on the recognition but not the category judgment task constitutes a functional dissociation between the two tasks. This result provides converging empirical support for the claim that participants were indeed test unaware in the category judgment task.

\section{EXPERIMENT 2}

In Experiment 2, we sought converging evidence for our conclusion that the slower performance for incongruous targets on the category judgment task was specific to the association established at study. As before, partici- pants were presented with congruous (napkin) and incongruous targets (computer) paired with a category (things found in a restaurant). At test, however, incongruous objects (computer) were re-paired with other studied categories (things found in a park) in the control group or paired with the original studied category in the experimental group (restaurant). This comparison between the two groups allowed us to establish that (1) slower responses to incongruous objects reflected a specific conceptual association established at study, rather than slow responses to all studied objects, irrespective of the association established at study; and (2) slower responses to incongruous objects were not simply due to the repetition of the studied items (computer and restaurant), even though they were changed in modality. Our prediction, therefore, was that slower responses to studied incongruous objects would be obtained only when the studied pair was repeated at test.

\section{Method}

Participants. One hundred and one undergraduates from the State University of New York at Stony Brook provided informed consent and participated in the experiment in partial fulfillment of a course requirement.

Materials. The study and test stimuli were identical to those used in Experiment 1 for the experimental group. In other words, the experimental group constituted a direct replication of the implicit category judgment condition in Experiment 1. For the control group. incongruous targets were re-paired with different studied ad hoc categories in the test phase. These stimuli were normed with 20 participants to ensure their suitability as incongruous targets for the new pairing.

Design and Procedure. The design and procedure were similar to those of Experiment 1, except that 40 participants were assigned to the control group and 40 others to the experimental group. For the control group, re-paired object-category pairs were presented at test.

\section{Results and Discussion}

Table 2 presents the response time and accuracy data on the category judgment task for the experimental and control groups, respectively. None of the participants in the control group showed any awareness that the test was a memory test. One participant from the experimental group who was test aware was replaced.

For the experimental group, as in Experiment 1, mean response time to incongruous targets (computer) was $126 \mathrm{msec}$ slower when the targets were studied than when they were not $[t(39)=2.89, S E=43.78, p<.006]$. Al-

Table 2

Mean Response Times (RTs, in Milliseconds) and Accuracy (in Proportions) for Correct Category Judgments in the Experimental and Control Groups in Experiment 2

\begin{tabular}{|c|c|c|c|c|c|c|c|c|}
\hline \multirow[b]{2}{*}{ Group } & \multicolumn{2}{|c|}{$\begin{array}{c}\text { Incongruous Target } \\
\text { (computer) }\end{array}$} & \multicolumn{2}{|c|}{$\begin{array}{c}\text { Congruous Target } \\
\text { (napkin) }\end{array}$} & \multicolumn{2}{|c|}{$\begin{array}{l}\text { Incongruous Distractor } \\
\text { (wrench, wind chime) }\end{array}$} & \multicolumn{2}{|c|}{$\begin{array}{l}\text { Congruous Distractor } \\
\text { (salt shaker, wineglass }\end{array}$} \\
\hline & RT & Accuracy & RT & Accuracy & RT & Accuracy & RT & Accuracy \\
\hline \multicolumn{9}{|l|}{ Experimental } \\
\hline Studied & 2,056 & .92 & 1,752 & .96 & 1,867 & .92 & 1,969 & .90 \\
\hline Nonstudied & 1,929 & .94 & 1,804 & .91 & 1,892 & .93 & 1,926 & .90 \\
\hline \multicolumn{9}{|l|}{ Control } \\
\hline Studied & 1,970 & .97 & 1,879 & .91 & 2,096 & .94 & 2,063 & .85 \\
\hline Nonstudied & 1,983 & .98 & 1,932 & .91 & 2,071 & .94 & 2,095 & .85 \\
\hline
\end{tabular}


though this inhibition effect failed to reach significance for accuracy $[t(39)=1.57, S E=.01, p<.12]$, it was in the expected direction. For studied congruous objects, the facilitation effect failed to reach significance in latency, as in Experiment $1[t(39)=1.08, S E=48.69]$, but this effect was significant in the accuracy data $[t(39)=2.68, S E=$ $.02, p<.01]$. No differences in response times were observed for congruent (wineglass) and incongruent (wrench) distractors between studied and nonstudied categories, as in Experiment $1[t<1$, and $t(39)=1.60, S E=26.39, p>$ .10 , respectively]. Similarly, accuracy data did not reveal any differences $(t \mathrm{~s}<1)$.

Once again, the slower responses to studied incongruous targets in the experimental group confirm the development of rapid new conceptual associations observed in Experiment 1 . The question of interest then is whether this pattern of slower responses to studied incongruous targets reflects a specific association formed at study between the target and the category.

The results of the control group indicate that the slower response times to incongruous targets is indeed a result of a specific conceptual association between the target and the category, and not due to a general slowing of responses to all studied targets due to their repetition. In the control group, a 13-msec reversed difference was found between the studied and nonstudied incongruous targets $[t<1$ for latency, $t(39)=1.29, S E=.01$ for accuracy]. This finding stands in sharp contrast to the markedly slow response times that were observed in Experiments 1 and 2 when the pairings between targets and categories at test repeated the relationship established at study. Therefore, the results of the control group suggest that a highly specific association was formed between the incongruous target and the ad hoc category at study. This association-specific priming was obtained in the category judgment task despite a change in the format of the stimuli across study and test, a change in modality, and despite the lack of test awareness in participants.

The effects of facilitation for congruous targets once again failed to reach significance, in the control group and in the experimental group $[t(39)=1.10, S E=48, p>.10$ for latency, $t<1$ for accuracy]. As discussed earlier, this result probably reflects decreased attentional resources for congruous targets relative to incongruous targets (Mulligan \& Hartman, 1996). No differences were obtained in the analysis of the distractors (all $t \mathrm{~s}<1$ ).

\section{GENERAL DISCUSSION}

In this article, we report that new associations can be retrieved within the conceptual domain through implicit memory. Although this result has been demonstrated earlier in the literature, our study represents a departure from earlier findings because it eliminates two potential problems in the interpretation of earlier studies. First, our results cannot be attributed to perceptual reprocessing of the cue-target pair because the cue-target pair was not repeated in the same format at study and test and because the modality of the cue-target pair was changed from study to test. Second, the association-specific priming observed in these experiments cannot be attributed to test awareness in participants because we eliminated test-aware participants from our analysis. In addition, the presence of a functional dissociation between the category judgment and episodic recognition tasks (i.e., the presence of reconstructive errors on the episodic recognition but not on the implicit category judgment test) supports the hypothesis that participants were indeed test unaware in the implicit category judgment task. Together, the results of Experiments 1 and 2 demonstrate for the first time that new associations can be retrieved through implicit memory despite the lack of perceptual or episodic support.

These findings suggest that the ability to retrieve contextual associations may not be unique to episodic memory, as suggested by some theorists (e.g., Bower, 1996). We speculate that episodic memory may be required for specific types of contextual associations (e.g., those that require a spatial or temporal context). At this point, however, future research should focus on the limits on the types of associations that can be retrieved through implicit memory.

\section{REFERENCES}

Bower, G. H. (1996). Reactivating a reactivation theory of implicit memory. Consciousness \& Cognition, 5, 27-72.

Bowers, J. S., \& SCHACTER, D. L. (1990). Implicit memory and test awareness. Journal of Experimental Psychology: Learning, Memory, \& Cognition, 16, 404-416.

Carlesimo, G. A. (1994). Perceptual and conceptual priming in amnesic and alcoholic patients. Neuropsychologia, 32, 903-921.

Dosher, B. A., \& Rosedale, G. (1991). Judgments of semantic and episodic relatedness: Common time course and failure of segregation. Journal of Memory \& Language, 30, 125-160.

GoSHEN-GotTstein, Y., \& Moscovitch, M. (1995a). Repetition priming for newly formed and preexisting associations: Perceptual and conceptual influences. Journal of Experimental Psychology: Learning, Memory, \& Cognition, 21, 1229-1248.

Goshen-GotTstein, Y., \& Moscovitch, M. (1995b). Repetition priming effects for newly formed associations are perceptually based: Evidence from shallow encoding and format specificity. Journal of Experimental Psychology: Learning, Memory, \& Cognition, 21, 1249 1262.

Graf, P., \& Mandler, G. (1984). Activation makes words more accessible, but not necessarily more retrievable. Journal of Verbal Learning \& Verbal Behavior, 23, 553-568.

Graf, P., \& SChacter, D. L. (1985). Implicit and explicit memory for new associations in normal and amnesic subjects. Journal of Experimental Psychology: Learning, Memory, \& Cognition, 11, 501-518.

Graf. P., \& SChacter, D. L. (1987). Selective effects of interference on implicit and explicit memory for new associations. Journal of Experimental Psychology: Learning, Memory, \& Cognition, 13, 45-53.

Graf, P., \& SCHACTER, D. L. (1989). Unitization and grouping mediate dissociations in memory for new associations. Journal of Experimental Psychology: Learning, Memory, \& Cognition, 11, 385-395.

Graf, P., Shimamura, A. P., \& Squire, L. R. (1985). Priming across modalities and priming across category levels: Extending the domain of preserved functioning in amnesia. Journal of Experimental Psychology: Learning. Memon: \& Cognition, 11, 501-518.

Hamann. S. B., \& Squire. L. R. (1995). On the acquisition of new declarative knowledge in amnesia. Behavioral Neuroscience, 109, 10271044

Hayman, C. A. G.. MacDonald. C. A.. \& Tulving, E. (1992). The role 
of repetition and associative learning in amnesia: A case experiment. Journal of Cognitive Neuroscience, 5, 376-389.

Howard, D. V., FrY, A. F., \& Brune, C. M. (1991). Aging and memory for new associations: Direct versus indirect measures. Journal of Experimental Psychology: Learning, Memory, \& Cognition, 17, 779792.

JACOBY, L. L., WolOSHYN, V., \& KeLLEY, C. (1989). Becoming famous without being recognized: Unconscious influences of memory produced by dividing attention. Journal of Experimental Psychology: General, 118, 115-125.

MAYES, A. E., \& GoOdING, P. (1989). Enhancement of word completion priming in amnesics by cuing with previously novel associates. Neuopsychologia, 27, 1057-1072.

Moscovitch, M., Winocur, G., \& McLachlan, D. (1986). Memory as assessed by recognition and reading time in normal and memory impaired people with Alzheimer's disease and other neurological disorders. Journal of Experimental Psychology: General, 115, 331-346.

Mulligan, N. W. (1997). Attention and implicit memory tests: The effects of varying attentional load on conceptual priming. Memory \& Cognition, 25, 11-17.

Mulligan, N. W., \& Hartman, M. (1996). Divided attention and indirect memory tests. Memory \& Cognition, 24, 453-465.

Musen, G., \& SQuire, L. R. (1993). On the implicit learning of novel associations by amnesic patients and normal subjects. Neuropsychology, 2, 119-135

Paller, K. A., \& Mayes, A. R. (1994). New association priming of word identification in normal and amnesic subjects. Cortex, 30, 53 73

Parkin, A. J. (1983). The relationship between orienting tasks and the structure of memory traces: Evidence from false recognition. British Journal of Psychology, 74, 61-69.

Poldrack, R. A., \& CoHEN, N. J. (1997). Priming of new associations in reading time: What is learned? Psychonomic Bulletin \& Review, 4, 398-402

Rajaram, S., \& Coslett, H. B. (2000). Acquisition and transfer of new verbal information in amnesia: Retrieval and neuroanatomical constraints. Neuropsychology, 14, 427-455.

Rajaram, S., \& Roediger, H. L., III (1993). Direct comparison of four implicit tests. Journal of Experimental Psychology: Learning, Memory, \& Cognition, 19, 765-776.

Reingold, E. M., \& Goshen-Gottstein, Y. (1996). Separating consciously controlled and automatic influences in memory for new associations. Journal of Experimental Psychology: Learning, Memory, \& Cognition, 22, 397-406.

Roediger, H. L., III, Weldon, M. S., \& Challis, B. H. (1989). Explaining dissociations between implicit and explicit measures of retention: A processing account. In H. L. Roediger, III, \& F. I. M. Craik
(Eds.), Varieties of memory and consciousness: Essays in honour of Endel Tulving (pp. 3-14). Hillsdale, NJ: Erlbaum.

Schacter, D. L., \& Graf, P. (1986). Preserved learning in amnesic patients: Perspectives from research on direct priming. Journal of Clinical \& Experimental Neuropsychology, 8, 727-783.

SChacter, D. L., \& Graf, P. (1989). Modality specificity of implicit memory for new associations. Journal of Experimental Psychology: Learning, Memory, \& Cognition, 15, 3-12.

SCHMidT, S. R. (1991). Can we have a distinctive theory of memory? Memory \& Cognition, 19, 523-542.

Shimamura, A. P., \& SQuire, L. R. (1989). Impaired priming of new associations in amnesia. Journal of Experimental Psychology: Learning, Memory, \& Cognition, 15, 721-728.

SRINIVAS, K. (1993). Perceptual specificity in nonverbal priming. Journal of Experimental Psychology:Learning, Memory, \& Cognition, 19. $582-602$.

SRINIVAS, K., \& Roediger, H. L., III (1990). Classifying implicit memory tests: Category association and anagram solution. Journal of Memory \& Language, 29, 389-412.

Tulving, E., Hayman, C. A. G., \& MacDonald, C. (1991). Long-lasting perceptual priming and semantic learning in amnesia: A case experiment. Journal of Experimental Psychology: Learning, Memory. \& Cognition, 7, 595-617

WELDON, M. S., \& Roediger, H. L., III (1987). Altering retrieval demands reverses the picture superiority effect. Memory \& Cognition, $15,269-280$.

\section{NOTE}

1. Goshen-Gottstein and Moscovitch (1995a) observed modality specificity for related but not unrelated cue-target pairs in their measure of association-specific priming (i.e., the difference between intact pairs and recombined pairs). On the face of it, this pattern suggests that associationspecific priming occurred for new associations independent of modality. However, the results are not entirely clear because the numerical priming in latency that occurred for unrelated cue-target pairs in the same modality condition $(1,124 \mathrm{vs} .1,161 \mathrm{msec}$ in the studied and nonstudied conditions, respectively) was eliminated in the different modality condition $(1,066$ vs. $1,064 \mathrm{msec}$ in the studied and nonstudied conditions, respectively). Thus a change in baseline from the recombined condition to the nonstudied condition alters the interpretation of the results. As a result, the issue of whether modality-independent associative priming occurred for new associations remains unresolved.

(Manuscript received May 3, 1999; revision accepted for publication September 30, 1999.) 